\title{
Proporsi Vanillylmandelic Acid Urin pada Pasien Terduga Tumor Neuroendokrin: Hubungannya dengan Usia dan Jenis Kelamin
}

\author{
The proportion of Urinary Vanillylmandelic Acid in Suspected \\ Neuroendocrine Tumor Patients: Its Association with Age and Gender
}

\author{
Annada Sofia ${ }^{1}$, Mohamad Sadikin ${ }^{2}$, Sri Widia A. Jusman ${ }^{2}$, Septelia Inawati Wanandi ${ }^{2}$, Ani \\ Retno Prijanti ${ }^{2}$, Novi Silvia Hardiany ${ }^{2 *}$ \\ ${ }^{1}$ Program Studi Pendidikan Dokter, Fakultas Kedokteran, Universitas Indonesia, Jakarta, 10430, Indonesia \\ ${ }^{2}$ Departemen Biokimia dan Biologi Molekuler, Fakultas Kedokteran, Universitas Indonesia, Jakarta, 10430, \\ Indonesia \\ *E-mail: novi.silvia@ui.ac.id; novish98@gmail.com
}

\begin{abstract}
Cancer prevalence in Indonesia is 1.8 per 1000 population in 2018. Early diagnosis is needed to reduce the mortality rate and one of which is by examining vanillylmandelic acid (VMA) level as tumor markers. VMA is a catecholamine metabolite whose level will increase in several neuroendocrine tumors. This study was conducted to determine the proportion of positive VMA in urine of patients with suspected neuroendocrine tumors in Jakarta and its association with age and gender. This study was a cross-sectional design using secondary data of urinary VMA laboratory examination from 295 patients who suspected neuroendocrine tumors period 2010 to 2019 in Laboratory of Department of Biochemistry and Molecular Biology, Faculty of Medicine Universitas Indonesia. Qualitative examination of urinary VMA used spot test. Positive examination result showed levels of $V M A$ in urine $>8 m g / 24$ hours, while negative result showed $\leq 8 m g / 24$ hours. Inclusion criteria were subject data with a provisional diagnosis of neuroblastoma, pheochromocytoma, and paraganglioma. The proportion of positive VMA in urine of suspected neuroendocrine tumor patients was 14,2\%. There was a significant association between VMA in urine with age (p 0,023), while gender was not significant $(p 0,885)$. In conclusion, there was an association between urinary VMA of suspected neuroendocrine tumor patients with age, however no association with gender.
\end{abstract}

Keywords: neuroendocrine tumors; urinary vanillylmandelic acid; age; gender

\begin{abstract}
Abstrak
Prevalensi kanker di Indonesia pada 2018 adalah 1,8 per 1000 penduduk. Diagnosis dini dibutuhkan untuk mengurangi angka mortalitas, salah satunya melalui pemeriksaan penanda tumor berupa vanillylmandelic acid (VMA). VMA termasuk metabolit katekolamin yang meningkat produksinya pada beberapa tumor neuroendokrin. Penelitian dilakukan untuk mengetahui proporsi VMA positif dalam urin pasien dugaan tumor neuroendokrin di Jakarta serta hubungannya dengan usia dan jenis kelamin. Penelitian ini menggunakan desain cross-sectional yang menggunakan data sekunder hasil pemeriksaan laboratorium VMA urin dari 295 pasien dugaan tumor neuroendokrin periode 2010 hingga 2019 di Laboratorium Departemen Biokimia dan Biologi Molekuler, Fakultas Kedokteran Universitas Indonesia. Data VMA kualitatif yang diperoleh, diperiksa dengan metode spot test. Hasil positif menunjukkan kadarnya $>8 \mathrm{mg} / 24 \mathrm{jam}$, sedangkan hasil negatif menunjukkan kadarnya $\leq 8 \mathrm{mg} / 24$ jam. Kriteria inklusi berupa diagnosis sementara neuroblastoma, pheochromocytoma, dan paraganglioma. Proporsi VMA positif dalam urin pasien dugaan tumor neuroendokrin adalah 14,2\%. Terdapat hubungan bermakna antara kadar VMA dalam urin dengan usia (p 0,023), sedangkan dengan jenis kelamin menunjukkan hasil yang tidak bermakna ( $p$ 0,885). Dengan demikian dapat disimpukan bahwa terdapat hubungan antara VMA urin pasien dugaan tumor neuroendokrin dengan usia, namun tidak terdapat hubungan dengan jenis kelamin.
\end{abstract}

Kata kunci: tumor neuroendokrin; vanillylmandelic acid urin; usia; jenis kelamin 


\section{Pendahuluan}

Data hasil Riset Kesehatan Dasar Kementerian Kesehatan Republik Indonesia 2018 menunjukkan bahwa prevalensi kanker di Indonesia meningkat dari 1,4 per 1000 penduduk pada 2013 menjadi 1,8 per 1000 penduduk pada 2018. Kanker menjadi salah satu penyebab kematian di dunia. Berdasarkan data dari International Agency for Research on Cancer (IARC), secara global terdapat sekitar 9,6 juta kematian akibat kanker pada 2018. Diagnosis sedini mungkin diperlukan untuk membantu mengurangi angka mortalitas akibat kanker. Tahapan diagnosis dini meliputi kesadaran mengenai gejala, evaluasi klinis, pemeriksaan diagnostik dan staging, serta perawatan yang sesuai. Gejala awal yang biasanya ditemukan adalah adanya massa atau tumor. Tumor nantinya dibedakan menjadi tumor jinak dan tumor ganas. Tumor ganas ini yang disebut sebagai kanker. $^{1-3}$

Pemeriksaan diagnostik yang dapat dilakukan salah satunya adalah pemeriksaan laboratorium. Pemeriksaan laboratorium dapat dilakukan untuk mendeteksi penanda tumor, salah satunya vanillylmandelic acid (VMA) yang merupakan metabolit katekolamin. VMA merupakan penanda untuk tumor yang menghasilkan katekolamin, yaitu neuroblastoma dan tumor neuroendokrin lainnya. Katekolamin terdiri atas norepinefrin, epinefrin, dan dopamin. Kadar katekolamin dapat dipengaruhi oleh usia dan jenis kelamin. Seiring pertambahan usia, kadar norepinefrin dalam plasma dan urin meningkat, sedangkan kadar epinefrin dalam plasma cenderung menurun. Pada perempuan didapatkan kadar epinefrin dalam urin yang lebih rendah daripada laki-laki. ${ }^{3-5}$

Peningkatan kadar VMA dideteksi dalam urin pasien dan disebut sebagai VMA positif dalam urin. Data hasil penelitian dari Departemen Ilmu
Kesehatan Anak Fakultas Kedokteran Universitas Indonesia Rumah Sakit Cipto Mangunkusumo pada 2009 menunjukkan bahwa proporsi pasien neuroblastoma yang memiliki VMA positif dalam urin adalah sekitar 13\%. Data tersebut didapatkan dari 62 pasien neuroblastoma pada tahun 2000 hingga 2007. ${ }^{6}$ Data proporsi VMA positif dalam urin pada pasien tumor neuroendokrin, termasuk neuroblastoma, dibutuhkan untuk mengetahui karakteristik tumor tersebut. Hubungan VMA positif dalam urin dengan usia dan jenis kelamin penting diketahui untuk mengidentifikasi faktor lain yang memengaruhi hasil pemeriksaan VMA dalam urin. Sampai saat ini, belum ada data mengenai proporsi VMA positif dalam urin pada tumor neuroendokrin serta hubungan VMA dalam urin dengan usia dan jenis kelamin di Jakarta maupun Indonesia. Oleh karena itu, tujuan penelitian ini yaitu untuk mengetahui proporsi VMA positif dalam urin pada pasien dengan dugaan tumor neuroendokrin di Jakarta serta hubungannya dengan usia dan jenis kelamin. Penelitian ini menggunakan data di Jakarta karena data hasil pemeriksaan VMA dalam urin pasien di Departemen Biokimia dan Biologi Molekuler, FKUI, Jakarta tersimpan dengan baik sehingga data sepuluh tahun terakhir dapat diakses.

\section{Metode}

Penelitian ini menggunakan desain observasional berupa analisis potong lintang. Data yang digunakan merupakan data sekunder berupa formulir dan hasil pemeriksaan satu kali VMA urin dari 295 pasien dengan dugaan tumor neuroendokrin periode 2010 hingga April 2019 di Laboratorium Departemen Biokimia dan Biologi Molekuler, Fakultas Kedokteran Universitas Indonesia, Jakarta. Pengumpulan data tersebut menggunakan metode consecutive sampling. Kriteria inklusi berupa diagnosis sementara yang tercantum dalam formulir pemeriksaan 
adalah neuroblastoma, pheochromocyto $m a$, atau paraganglioma. Kriteria eksklusi berupa tidak dicantumkannya diagnosis sementara.

Prosedur pemeriksaan VMA dalam urin yang digunakan adalah metode spot test. $^{7}$ Hasil pemeriksaan dinilai dengan membandingkan perbedaan atau perubahan warna. Prinsip pemeriksaan tersebut adalah reaksi antara VMA dengan diazotized p-nitroaniline yang menghasilkan warna violet. $^{8}$ Urin yang diperiksa merupakan sampel urin 24 jam. Bahan yang digunakan untuk pemeriksaan ini adalah campuran $1 \mathrm{ml}$ larutan paranitroaniline $0,2 \%, 1 \mathrm{ml}$ sodium nitrit $0,2 \%$, dan $2 \mathrm{ml}$ larutan potassium karbonat $10 \%$ yang kemudian disebut sebagai reagen. Sampel urin diteteskan 2 atau 3 tetes pada kertas saring hingga terbentuk tanda berdiameter $3 \mathrm{~cm}$, kemudian ditambahkan beberapa tetes larutan reagen. Perubahan warna diamati pada satu jam pertama. Tidak ada atau sedikit perubahan warna (tetap berwarna kekuningan seperti warna urin biasanya) dapat diinterpretasikan sebagai hasil negatif. Perubahan warna menjadi violet diinterpretasikan sebagai hasil positif. Pada pemeriksaan, diperlukan kontrol positif berupa standar VMA yang kemudian juga diteteskan larutan reagen. Perubahan warna pada sampel urin pasien dapat dibandingkan dengan standar VMA. Hasil positif mengindikasikan kadar VMA dalam urin lebih dari $8 \mathrm{mg} / 24$ jam, sedangkan hasil negatif mengindikasikan kadarnya kurang dari atau sama dengan 8 $\mathrm{mg} / 24 \mathrm{jam}$.

Data yang telah dikumpulkan diolah menggunakan Statistical Product and Service Solutions (SPSS) versi 20. Data tersebut melalui proses penyuntingan, pemberian kode, dan kemudian dimasukkan dalam program SPSS. Jenis data dalam penelitian ini adalah data kategorik. Data kategorik tersebut berupa kelompok usia, VMA dalam urin (positif atau negatif), dan jenis kelamin (laki-laki atau perempuan). Uji hipotesis yang digunakan adalah Chi Square untuk menganalisis hubungan variabel VMA dalam urin dengan jenis kelamin. Uji hipotesis hubungan variabel VMA dalam urin dengan kelompok usia menggunakan Chi Square atau uji alternatif berupa Mann Whitney karena kelompok usia lebih dari dua kategori. Kelompok usia dalam penelitian ini menggunakan standar WHO. ${ }^{9}$ Hasil uji hipotesis dua variabel dikatakan memiliki hubungan apabila nilai p lebih kecil dari 0,05 .

\section{Hasil}

Karaktersitik 295 subjek pada data sekunder menunjukkan sebanyak 52,5\% adalah laki-laki dan $47,5 \%$ adalah perempuan. Subjek penelitian ini didominasi oleh kelompok usia nol hingga empat tahun, yaitu sebesar $61,7 \%$ (Tabel 1). Jenis dugaan tumor neuroendokrin yang paling banyak ditemukan pada formulir pemeriksaan pasien adalah neuroblastoma (Tabel 1). Proporsi VMA positif dalam urin pasien dugaan tumor neuroendokrin di Jakarta adalah 14,2\% (Tabel 2).

Pada lembar formulir pemeriksaan tercantum diagnosis sementara tumor neuroendokrin yang meliputi neuroblastoma, pheochromocytoma, dan paraganglioma. Pheochromocytoma dan paraganglioma disatukan menjadi jenis tumor neuroendokrin yang sama karena paraganglioma adalah pheochromocytoma ekstraadrenal. Pada 254 neuroblastoma ditemukan sebanyak 15,4\% sampel VMA urin yang positif, sedangkan pada 41 pheochromocytoma ekstra adrenal hanya 7,3\% yang VMA urinnya positif (Tabel 3). Dari analisis Chi Square, tidak terdapat hubungan antara jenis tumor neuroendokrin dengan VMA dalam urin ( $p$ $=0.260$ ). Untuk menganalisis hubungan VMA urin dengan kelompok usia dilakukan dengan uji Mann-Whitney dan memberikan hasil yang bermakna ( $\mathrm{p}=$ 0,023) (Tabel 4). Analisis hubungan VMA 
urin dengan jenis kelamin dilakukan dengan uji Chi Square dan memberikan hasil yang tidak bermakna $(\mathrm{p}=0,885)$

(Tabel 5).

Tabel 1. Karakteristik data sekunder subjek penelitian

\begin{tabular}{lcc}
\hline Variabel & $\mathbf{N}$ & $\mathbf{\%}$ \\
\hline Jenis kelamin & 140 & 47,5 \\
Perempuan & 155 & 52,5 \\
Laki-laki & & \\
Usia (tahun) & 182 & 61,7 \\
$0-4$ & 52 & 17,6 \\
$5-9$ & 24 & 8,1 \\
$10-14$ & 6 & 2,0 \\
$15-19$ & 1 & 0,3 \\
$20-24$ & 6 & 2,0 \\
$25-29$ & 4 & 1,4 \\
$30-34$ & 3 & 1,0 \\
$35-39$ & 6 & 2,0 \\
$40-44$ & 2 & 0,7 \\
$45-49$ & 6 & 2,0 \\
$50-54$ & 2 & 0,7 \\
$55-59$ & 1 & 0,3 \\
$60+$ & & \\
Diagnosis Sementara & & 86,1 \\
Neuroblastoma & 254 & 13,2 \\
Pheochromocytoma & 39 & 0,7 \\
Paraganglioma & 2 & 100,0 \\
\hline Total & 295 & \\
\hline
\end{tabular}

Tabel 2. Proporsi VMA urin positif dan negatif

\begin{tabular}{lc}
\hline \multicolumn{1}{c}{ VMA dalam urin } & n (\%) \\
\hline Positif & $42(14,2)$ \\
Negatif & $253(85,8)$ \\
\hline Total & $295(100,0)$ \\
\hline
\end{tabular}

Tabel 3. Proporsi VMA berdasarkan jenis tumor

\begin{tabular}{|c|c|c|c|c|c|c|}
\hline & & \multicolumn{4}{|c|}{ VMA dalam urin } & \multirow{3}{*}{ Nilai $p$} \\
\hline & & \multicolumn{2}{|c|}{ negatif } & \multicolumn{2}{|c|}{ positif } & \\
\hline & & $\mathrm{n}$ & $\%$ & $\mathrm{n}$ & $\%$ & \\
\hline \multirow{2}{*}{$\begin{array}{l}\text { Jenis Tumor } \\
\text { Neuroendokrin }\end{array}$} & Neuroblastoma & 215 & 84,6 & 39 & 15,4 & 0,260 \\
\hline & $\begin{array}{l}\text { Pheochromocytoma }+ \\
\text { Paraganglioma }\end{array}$ & 38 & 92,7 & 3 & 7,3 & \\
\hline Total & & 253 & 85,8 & 42 & 14,2 & \\
\hline
\end{tabular}


Tabel 4. Analisis hubungan VMA urin dengan usia

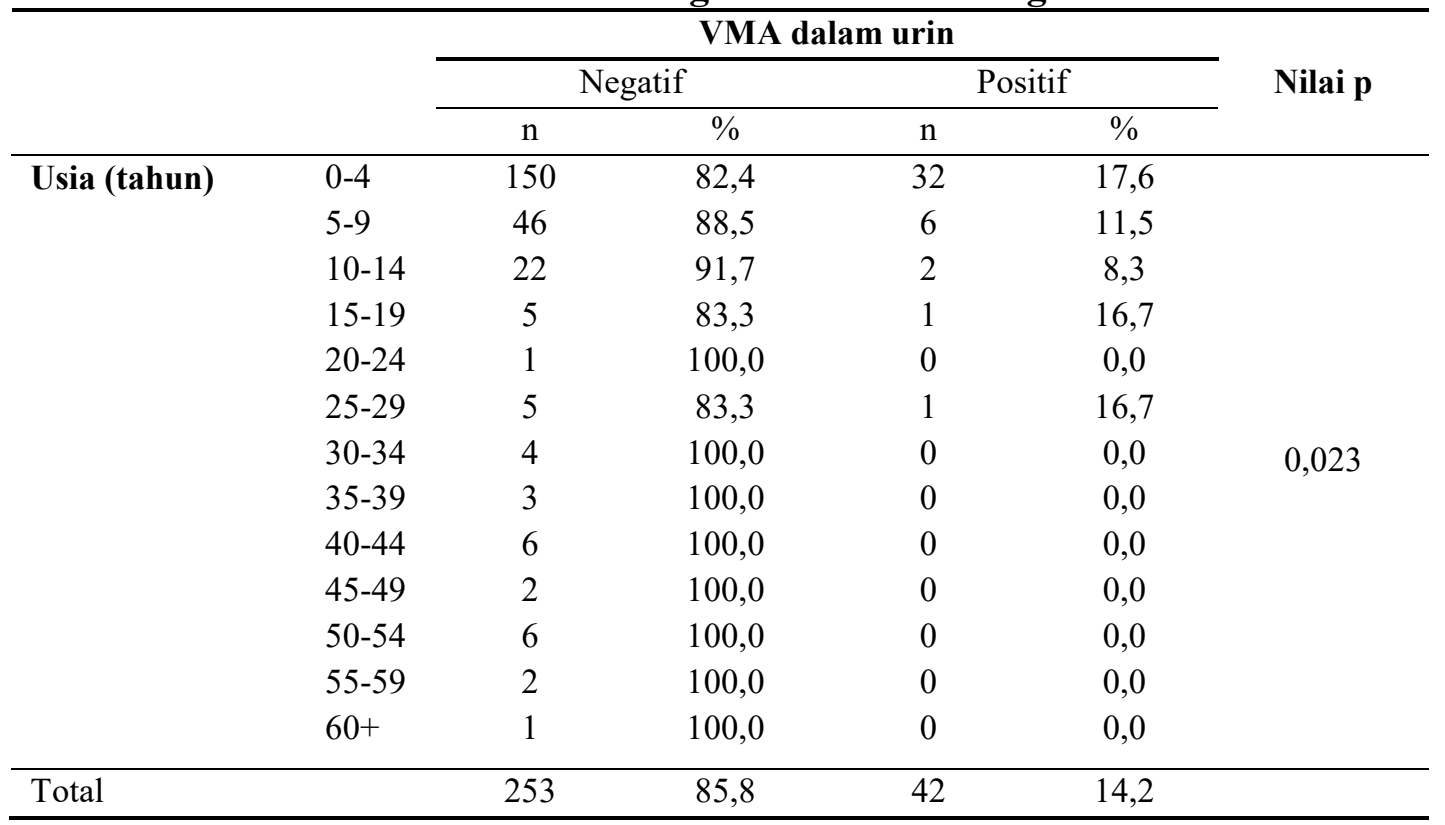

Tabel 5. Analisis hubungan VMA urin dengan jenis kelamin

\begin{tabular}{|c|c|c|c|c|c|c|}
\hline & & \multicolumn{4}{|c|}{ VMA dalam urin } & \multirow{3}{*}{ Nilai p } \\
\hline & & \multicolumn{2}{|c|}{ Negatif } & \multicolumn{2}{|c|}{ Positif } & \\
\hline & & $\mathrm{n}$ & $\%$ & $\mathrm{n}$ & $\%$ & \\
\hline \multirow[t]{2}{*}{ Jenis kelamin } & Perempuan & 121 & 86,4 & 19 & 13,6 & \multirow{2}{*}{0,885} \\
\hline & Laki-laki & 132 & 85,2 & 23 & 14,8 & \\
\hline Total & & 253 & 85,8 & 42 & 14,2 & \\
\hline
\end{tabular}

\section{Pembahasan}

Karakteristik subjek dari aspek jenis kelamin hampir sama jumlahnya antara perempuan dan laki-laki. Hal ini sesuai dengan data epidemiologi bahwa kejadian tumor neuroendokrin secara keseluruhan tidak jauh berbeda antara lakilaki dan perempuan. ${ }^{10}$ Subjek penelitian ini didominasi kelompok usia anak dan jenis tumor neuroendokrin berupa neuroblastoma. Hal ini karena neuroblastoma merupakan tumor padat ekstrakranial yang paling sering terjadi pada anak. $^{11}$

Hasil penelitian ini menunjukkan bahwa proporsi VMA positif dalam urin pasien dugaan tumor neuroendokrin di Jakarta adalah 14,2\%. Jika dihitung secara terpisah, proporsi VMA positif dalam urin pasien dugaan neuroblastoma adalah $15,4 \%$ dan proporsi VMA positif dalam urin pasien dugaan pheochromocytoma termasuk paraganglioma adalah 7,3\% (Tabel 3). Studi Garniasih $\mathrm{dkk}^{6}$ menampilkan proporsi VMA positif dalam urin pasien neuroblastoma adalah 12,8\% dari 62 pasien dalam periode 2000 hingga 2007. Studi Aydin dkk ${ }^{12}$ memberikan hasil proporsi VMA positif dalam urin pasien neuroblastoma sebesar $41,7 \%$ dengan jumlah total subjek penelitian 444 orang dalam periode 33 tahun. Data-data tersebut menunjukkan bahwa tidak semua neuroblastoma dan pheochromocytoma memberikan hasil VMA positif dalam urin pada pemeriksaan kualitatif. Hal ini terjadi karena terdapat jenis neuroblastoma dan pheochromocytoma yang menghasilkan metabolit katekolamin dalam jumlah sedikit sehingga tidak terdeteksi sebagai VMA positif dalam urin pada pemeriksaan kualitatif. $^{8} \quad$ Pada studi Aydin dkk, ${ }^{12}$ kelangsungan hidup pasien neuroblastoma 
lebih tinggi pada kelompok dengan hasil VMA negatif dalam urin. VMA positif dalam urin ditemukan sebagai faktor prognostik buruk bagi pasien neuroblastoma yang lokasi tumor primernya berada di leher, toraks, dan pelvis. Pada pasien dengan risiko tinggi, hasil negatif pada pemeriksaan VMA dalam urin menunjukkan prognosis yang lebih baik. ${ }^{12}$

Peningkatan produksi katekolamin pada pasien tumor neuroendokrin tidak hanya dapat dideteksi melalui pemeriksaan kualitatif VMA dalam urin. Hasil lebih akurat dapat diperoleh melalui pemeriksaan kuantitatif VMA dalam urin. Pemeriksaan kualitatif dengan spot test kurang sensitif untuk mendeteksi peningkatan katekolamin pada tumor neuroendokrin. Namun, pemeriksaan dengan metode spot test memiliki beberapa keunggulan, yaitu prosedur pemeriksaan yang sederhana, dapat dilakukan hanya dengan dua atau tiga tetes urin, sampel urin tidak harus berasal dari urin segar (tidak harus segera setelah berkemih), dan reagen mudah didapatkan. ${ }^{7}$ Studi Aydin $\mathrm{dkk}^{12}$ menunjukkan bahwa pasien dengan hasil pemeriksaan kualitatif negatif dapat memiliki peningkatan kadar VMA dalam urin secara kuantitatif. Data ini memperkuat bahwa metode terbaik untuk mengetahui peningkatan VMA dalam urin adalah dengan high performance liquid chromatography coupled with electrochemical detection (HPLC-ECD) ataupun metode pemeriksaan kuantitatif lainnya. ${ }^{13}$ Hasil VMA positif dalam urin lebih banyak didapatkan pada pasien dengan stadium tumor yang tinggi. ${ }^{12}$

Pada neuroblastoma, jumlah relatif metabolit katekolamin dalam urin dipengaruhi oleh derajat maturasi dari selsel tumor yang berasal dari neural crest. ${ }^{11}$ Peningkatan VMA dalam urin dapat terjadi pada 95\% kasus neuroblastoma. ${ }^{14}$ Pada pheochromocytoma, metanefrin lebih spesifik untuk digunakan sebagai penanda tumor yang berasal dari sel-sel kromaffin. ${ }^{15}$ Studi Martinez-Morillo dkk. menunjukkan pemeriksaan metanefrin dalam urin memiliki sensitivitas 91,7\% untuk mendeteksi pheochromocytoma dan paraganglioma. ${ }^{16}$ Studi Davidson dkk menunjukkan bahwa enam dari sebelas penderita pheochromocytoma atau paraganglioma mengalami peningkatan VMA dalam urin. Studi tersebut menggunakan metode HPLC-ECD. ${ }^{17}$ Rendahnya proporsi VMA positif dalam urin pada penelitian ini dapat disebabkan oleh berbagai hal, salah satunya adalah diagnosis tumor neuroendokrin yang masih sementara dan belum sebagai diagnosis pasti. Diagnosis sementara artinya belum berarti semua subjek penelitian ini pasti menderita neuroblastoma atau pheochromocytoma. Selain itu, cara pengumpulan urin juga dapat menjadi salah satu faktor yang memengaruhi hasil. Sebagian sampel bersumber dari urin sewaktu dan sebagian lagi menggunakan urin 24 jam. ${ }^{18}$ Karakteristik tumor neuroendokrin yang lebih spesifik belum dapat diketahui dari penelitian ini.

Analisis secara statistik pada penelitian ini menunjukkan adanya hubungan antara VMA dalam urin dengan kelompok usia. Hubungan tersebut dianalisis berdasarkan trend menggunakan uji Mann-Whitney. Dari hasil analisis tersebut, VMA positif dalam urin lebih banyak ditemukan pada kelompok usia anak. Semakin muda kelompok usia, semakin banyak ditemukan hasil VMA positif dalam urin. Hasil ini menunjukkan bahwa pasien anak dengan dugaan tumor neuroendokrin lebih cenderung memberikan hasil VMA dalam urin positif. Kelompok usia dengan jumlah hasil positif paling banyak adalah usia nol hingga empat tahun atau kurang dari lima tahun. Neuroblastoma paling sering terjadi pada anak dan jarang terjadi pada remaja dan dewasa muda, sedangkan pheochromocytoma dapat terjadi pada berbagai usia. ${ }^{11,19}$ Berdasarkan fakta 
tersebut, gabungan pasien dugaan neuroblastoma dan pheochromocytoma memang akan didominasi oleh usia anak. Sekitar $40 \%$ pasien neuroblastoma didiagnosis pada usia bayi dan 90\% didiagnosis pada usia di bawah 10 tahun. ${ }^{11}$ Neuroblastoma dapat terjadi pada remaja dan dewasa muda, tetapi hanya kurang dari $5 \%$ dari seluruh kasus. ${ }^{11}$

Pada studi Garniasih $\mathrm{dkk}^{6}$ usia terbanyak saat diagnosis adalah satu hingga kurang dari lima tahun. Studi Davidson $\mathrm{dkk}^{17}$ menampilkan hasil bahwa pheochromocytoma pada anak terjadi pada rentang usia 5 hingga 18 tahun, sedangkan $69 \%$ neuroblastoma pada usia di bawah lima tahun. Terdapat beberapa studi terkait hubungan VMA dalam urin dengan usia dan memiliki hasil yang beragam. Studi Aydin $\mathrm{dkk}^{12}$ memberikan hasil tidak adanya hubungan signifikan antara usia dengan VMA dalam urin. Saxena $\mathrm{dkk}^{5}$ menemukan adanya efek sederhana dari usia terhadap norepinefrin pada plasma dan urin. Pada studi tersebut, peningkatan usia sejalan dengan peningkatan kadar norepinefrin pada plasma. Namun, studi tersebut bukan dilakukan pada pasien tumor neuroendokrin dan kadar katekolamin dalam plasma tidak berkorelasi erat dengan kadar katekolamin dalam urin. Sementara itu, studi Barco $\mathrm{dkk}^{13}$ yang menggunakan HPLC-ECD juga menunjukkan adanya hubungan signifikan antara kelompok usia dengan VMA dalam urin.

VMA dalam urin dengan jenis kelamin tidak memiliki hubungan berdasarkan hasil penelitian ini. Hal ini sesuai dengan hasil studi Aydin dkk yang menampilkan tidak adanya hubungan signifikan antara jenis kelamin dengan status VMA. ${ }^{12}$ Studi Davidson $\mathrm{dkk}^{17}$ menunjukkan tidak ada perbedaan signifikan antara perempuan dan laki-laki. Tidak adanya perbedaan signifikan antara perempuan dan laki-laki pada pemeriksaan VMA juga didapatkan dari studi Barco $\mathrm{dkk}^{13}$ yang menggunakan HPLC-ECD.
Studi Saxena $\mathrm{dkk}^{5}$ menunjukkan bahwa kadar epinefrin dalam plasma dan urin serta kadar norepinefrin dalam urin lebih rendah pada perempuan. Perbedaan dari setiap hasil penelitian dipengaruhi oleh berbagai faktor, salah satunya adalah besar sampel dan karakteristik subjek. Namun, hingga saat ini batas normal VMA dalam urin tidak dibedakan berdasarkan jenis kelamin. Dalam kondisi istirahat, konsentrasi epinefrin dan norepinefrin (katekolamin) pada perempuan dan lakilaki relatif sama. ${ }^{20}$

Keterbatasan pada penelitian ini yaitu menggunakan data sekunder berupa lembar hasil pemeriksaan dan formulir pemeriksaan yang hanya mencantumkan diagnosis sementara sehingga tidak dapat memberikan nilai proporsi yang tepat untuk pasien dengan diagnosis pasti tumor neuroendokrin, serta tidak dapat mengetahui faktor-faktor lain yang mungkin berpengaruh terhadap kadar VMA dalam urin pasien. Keterbatasan penelitian ini juga meliputi desain penelitian yang menggunakan potong lintang serta tidak dilakukannya analisis multivariat. Hasil pemeriksaan VMA dalam urin berupa data kualitatif sehingga tidak dapat membandingkan kadar peningkatan VMA dalam urin pada kelompok usia atau jenis kelamin yang berbeda.

\section{Kesimpulan}

Proporsi VMA positif dalam urin pasien dugaan tumor neuroendokrin di Jakarta periode 2010 hingga April 2019 adalah 14,2\%. Proporsi VMA urin tersebut berhubungan dengan usia pasien, namun tidak berhubungan dengan jenis kelamin.

\section{Saran}

Penelitian selanjutnya diperlukan untuk menilai proporsi VMA positif pada pasien yang sudah terdiagnosis tumor neuroendokrin. Pemeriksaan VMA dalam urin sebagai salah satu metode diagnosis 
neuroblastoma dan pheochromocytoma lebih utama menggunakan pemeriksaan kuantitatif daripada kualitatif. Penelitian selanjutnya diharapkan mampu melakukan analisis multivariat terhadap berbagai faktor, termasuk faktor kondisi klinis pasien dan parameter biomedis lainnya.

\section{Daftar Rujukan}

1. Badan Penelitian dan Pengembangan Kementerian Kesehatan RI. Hasil Utama Riset Kesehatan Dasar. Jakarta: Kementerian Kesehatan Republik Indonesia; 2018.

2. World Health Organization (WHO). Latest global cancer data. Int Agency Res Cancer [Internet]. 2018. Available from: https://www.iarc.fr/wpcontent/uploads/2018/09/pr263_E.pdf

3. WHO. Guide to cancer early diagnosis. Geneva: World Health Organization; 2017.

4. Shen Y, Li H, Lu J, Luo X, Guan Q, Cheng L. Analytical validation and clinical application of urinary vanillylmandelic acid and homovanillic acid by LC-MS/MS for diagnosis of neuroblastoma. Biomed Chromatogr. 2019;33(6).

5. Saxena AR, Chamarthi B, Williams GH, Hopkins PN, Seely EW. Predictors of plasma and urinary catecholamine levels in normotensive and hypertensive men and women. J Hum Hypertens. 2014;28(5):292-7.

6. Garniasih RD, Windiastuti E, Gatot D. Karakteristik dan Kesintasan Neuroblastoma pada Anak di Departemen Ilmu Kesehatan Anak Fakultas Kedokteran Universitas Indonesia Rumah Sakit Cipto Mangunkusumo. Sari Pediatr. 2009;11(1):3946.

7. Evans AE, Blore J, Hadley R, Tanindi S. The LaBrosse spot test: a practical aid in the diagnosis and management of children with neuroblastoma. Pediatrics. 1971;47(5):913-5.

8. Cheung N-K V, Cohn SL. Neuroblastoma. Springer-Verlag Berlin Heidelberg. 2005. p. 8.

9. Ahmad OB, Boschi-pinto C, Lopez AD, Murray CJ, Lozano R, Inoue M. Age standardization of rates: a new WHO standard. GPE Discuss Pap Ser [Internet]. 2001;(31):1-14. Available from: http://www.who.int/healthinfo/paper31.pdf

10. Kilickap S, Hayran KM. Epidemiology of Neuroendocrine Tumors. In: Yalcin S, Aberg $\mathrm{K}$, editors. Neuroendocrine tumours: diagnosis and management. Springer-Verlag Berlin Heidelberg; 2015. p. 23-33.

11. Matthay KK, Maris JM, Schleiermacher G,
Nakagawara A, Mackall CL, Diller L, et al. Neuroblastoma. Nat Rev Dis Prim. 2016;2:121.

12. Aydin GB, Kutluk MT, Yalcin B, Varan A, Akyuz C, Buyukpamukcu M. The prognostic significance of vanillylmandellic acid in neuroblastoma. Pediatr Hematol Oncol. 2010;27(6):435-48.

13. Barco S, Gennai I, Reggiardo G, Galleni B, Barbagallo L, Maffia A, et al. Urinary homovanillic and vanillylmandelic acid in the diagnosis of neuroblastoma: report from the Italian cooperative group for neuroblastoma. Clin Biochem. 2014;47(9):848-52.

14. Kliegman RM, Stanton BF, St Geme III JW, Schor NF, Behrman RE. Nelson textbook of pediatrics. Edisi ke-20. Philadelphia: Elsevier; 2016. p. 2461-4.

15. Eisenhofer G, Peitzsch M. Laboratory evaluation of pheochromocytoma and paraganglioma. Clin Chem. 2014;60(12):1486-99.

16. Martínez-Morillo E, Valdés Gallego N, Eguia Ángeles E, Fernández Fernández JC, Prieto García B, Álvarez F V. Performance of plasma free metanephrines in diagnosis of pheochromocytomas and paragangliomas in the population of Asturias. Endocrinol Diabetes Nutr. 2019;66(5):312-9.

17. Davidson DF, Hammond PJ, Murphy D, Carachi R. Age-related medical decision limits for urinary free (unconjugated) metadrenalines, catecholamines and metabolites in random urine specimens from children. Ann Clin Biochem. 2011;48(4):35866.

18. Smith SJ, Diehl NN, Smith BD, Mohney BG. Urine catecholamine levels as diagnostic markers for neuroblastoma in a defined population: Implications for ophthalmic practice. Eye. 2010;24(12):1792-6.

19. Longo DL, Fauci AS, Kasper DL, Hauser SL, Jameson JL, Loscalzo J. Harrison's hematology and oncology. Edisi ke-2. McGraw-Hill Education, LLC; 2013. p. 6436.

20. Goldstein DS. Catecholamines 101. Clin Auton Res. 2010;20(6):331-52. 